\title{
Analysis of Local Conditions on Graphite Growth and Shape During Solidification of Ductile Cast Iron
}

Tiedje, Niels S.; Bjerre, Mathias K.; Azeem, Mohammed A.; Hattel, Jesper H.; Lee, Peter D.

Published in:

Transactions of the Indian Institute of Metals

Link to article, DOI:

10.1007/s12666-018-1448-z

Publication date:

2018

Document Version

Peer reviewed version

Link back to DTU Orbit

Citation (APA):

Tiedje, N. S., Bjerre, M. K., Azeem, M. A., Hattel, J. H., \& Lee, P. D. (2018). Analysis of Local Conditions on Graphite Growth and Shape During Solidification of Ductile Cast Iron. Transactions of the Indian Institute of Metals, 71(11), 2699-2705. https://doi.org/10.1007/s12666-018-1448-z

\section{General rights}

Copyright and moral rights for the publications made accessible in the public portal are retained by the authors and/or other copyright owners and it is a condition of accessing publications that users recognise and abide by the legal requirements associated with these rights.

- Users may download and print one copy of any publication from the public portal for the purpose of private study or research.

- You may not further distribute the material or use it for any profit-making activity or commercial gain

- You may freely distribute the URL identifying the publication in the public portal 


\section{Analysis of local conditions on graphite growth and shape during solidification of ductile cast iron.}

Associate Professor Niels S Tiedje (corresponding author)

Department of Mechanical Engineering, Technical University of Denmark, 2800 Kgs. Lyngby, Denmark.

Phone: +4545254719

Mobile: +4551418785

Fax: No longer available

Mail: nsti@mek.dtu.dk

Forecast Analyst Mathias K Bjerre

Ørsted, Nesa Allé 1, 2820 Gentofte, Denmark

Mail: $\underline{\text { marb@orsted.dk }}$

Note: For the work presented here, Mathias Bjerre was a PhD student at DTU Mechanical Engineering but is now employed at Ørsted.

Dr. Mohammed A Azeem mohammed.azeem@ucl.ac.uk,

Department of Mechanical Engineering, University College London, London, WC1E 7JE, United Kingdom

Research Complex at Harwell, RAL, Didcot, OX11 0FA, United Kingdom

Professor Jesper H Hattel jhat@mek.dtu.dk,

Department of Mechanical Engineering, Technical University of Denmark, 2800 Kgs. Lyngby, Denmark.

Peter D Lee peter.lee@ucl.ac.uk

Department of Mechanical Engineering, University College London, London, WC1E 7JE, United Kingdom

Research Complex at Harwell, RAL, Didcot, OX11 0FA, United Kingdom 


\title{
Analysis of local conditions on graphite growth and shape during solidification of ductile cast iron.
}

\begin{abstract}
3D X-Ray tomography recordings have been used to study graphite growth during solidification of ductile cast iron. Using data from such recordings, it is shown how local growth conditions influence growth rate and morphology of nodules during solidification. The experiments show that it is common for nodules to gradually change shape during solidification so that sphericity decreases. It is also shown that different shapes of nodules can evolve in direct contact with liquid iron and also after when they are encapsulated in austenite.

It is observed that a significant proportion of originally complete spherical nodules become less spherical via formation of protrusions on the surface, these new surfaces are observed to grow relatively faster.

It is shown that encapsulation of the graphite nodule by austenite may be incomplete, and that at the end of solidification, partial encapsulation and the effect of the number of nearest graphite nodules play a crucial role in determining the final graphite morphology.
\end{abstract}

\section{Keywords}

Ductile Cast Iron, X-Ray Tomography, Graphite Growth, Solidification,

\section{Introduction}

Ductile cast iron has been a commonly used construction material since its invention in the late 1940s, it has been increasingly used across various industries [1]. Ductile cast iron has properties resembling steel but with the added advantage of remarkable castability, thus they are preferred materials for cast components in many industries.

The mechanical properties and remarkable castability of cast irons is attributed to the formation of graphite spheres (nodules) during the course of solidification. Processing of the melt to obtain the right shape and size distribution of graphite particles is key to the manufacturing of high-quality cast products. It is commonly known that variations in melt treatment conditions, casting design and alloy composition, all influence the morphology, size and size distribution of graphite in cast irons [1]. Therefore, solidification of cast iron has been a topic of interest in the past decades. It has led to significant improvements in quality and predictability and also development of new alloys with improved properties.

It is also well known that further, significant improvements are possible if the coupling between melt treatment, solidification, formation of microstructures and the resulting mechanical properties 
are better understood, and particularly if better and more reliable models describing this interaction are available [2].

Several researchers have contributed to the understanding of factors influencing growth of graphite work that in 2017 was comprehensively compiled by Stefanescu in ASM Handbook [1]. The use of certain alloying elements to control the shape of graphite during solidification is extensively reported, we now know what causes graphite to grow in the form of spheres or flakes or intermediate forms [3-10]. However, in ductile cast irons, it is common to find a variation in graphite shape, size and distribution, which results in significant variations in mechanical properties [11]. This variation occurs in materials with nominally similar chemical composition and which, according to standards such as ISO-945 or ASTM A247, would be classified as having an acceptable microstructure. To understand the causes for such seemingly inexplicable variations in products, that from their specifications should be alike, it is necessary to investigate what causes minor variations in graphite shape and structure during solidification. The present paper shows how synchrotron X-ray tomography recordings of solidification of ductile cast iron can be used to analyse both individual particles and populations of graphite particles.

\section{Experiments}

To investigate precipitation of graphite during solidification of ductile cast iron an experiment was conducted on the I12 beam line at the Diamond Light Source synchrotron facility in which a cylindrical sample $2 \mathrm{~mm}$ in diameter and $8 \mathrm{~mm}$ long was melted and solidified. The DCI sample's composition was $3.6 \mathrm{wt} \% \mathrm{C}, 1.9 \mathrm{wt} \% \mathrm{Si}$ and $0.07 \mathrm{wt} \% \mathrm{Mg}$. To protect the sample from the surrounding atmosphere and to contain it during the experiment it was encapsulated in a quartz tube. Using an environmental cell described in detail by Azeem et al. [12], the sample was heated to above the melting point and then cooled at a rate of $0.03{ }^{\circ} \mathrm{C} / \mathrm{s}$ while $3 \mathrm{D}$ X-ray tomograms were recorded. Details on imaging, construction of tomograms and filtering follow the methodology developed in $[12,13]$ and are described in detail in $[14,15]$. Binary images for quantification of particle shape and volume were obtained by filtering and segmenting reconstructed $3 \mathrm{D}$ volumes based on grey level variations representing differences in attenuation. It was not possible to separate liquid melt from austenite due to the limited attenuation difference between the two phases.

Following the synchrotron experiments the sample was embedded in resin and serially sectioned. Sectioning was performed by polishing longitudinal sections of the cylindrical sample using $3 \mu \mathrm{m}$ and $1 \mu \mathrm{m}$ diamond suspensions in steps of roughly $20 \mu \mathrm{m}$. Each section was imaged in a light optical microscope (LOM). The method was used to capture microstructure in the sample from the surface to a distance of $1000 \mu \mathrm{m}$ (corresponding to the centre of the sample). In the central $150 \mu \mathrm{m}$ secondary electron images (SEIs) were obtained using a scanning electron microscope (SEM) and energy-dispersive X-ray spectroscopy (EDS) was used to map the chemical composition in selected representative regions.

\section{Results and discussion}


Figure 1a-f shows 2D sections of a sub-volume near the centre of the sample captured at different times and temperatures during solidification. The images show the formation of graphite particles (dark phase) during cooling. Since the sample composition is hypoeutectic, the primary austenite forms before the graphite. The austenite is not visible but it holds the graphite in place during solidification [15]. The corresponding 3D volumes are shown in Figure 1g-i. Figure $1 \mathrm{j}$ shows a SEM image of the serially sectioned sample in a region corresponding to that shown in figures la-f. The SEM image provides more detailed information, such as, internal structure of the graphite particles and reveals the nature of interface between the particle and the matrix. Thus the serial sectioning and microscopic analysis provides more detailed information on nature of the artefacts shown in the X-Ray tomography, and thus facilitates distinction between graphite, pores and inclusions. Figures $1 \mathrm{k}$ and 1 shows the result of element mapping of $\mathrm{Si}$ and $\mathrm{Mg}$ respectively on the section. In cast irons the Si content is high in first solidified austenite and it drops in the last to solidify liquid. Thus, in the current context, the Si map reveals the solidification sequence of the matrix surrounding the graphite. The $\mathrm{Mg}$ map highlights oxide particles so that they can be removed from the analysis of graphite nucleation and growth measurements.

The two graphite particles shown in Figure 1a and $\mathrm{g}$ form at approximately the same time, but their shapes and final sizes become significantly different during the course of solidification. The final size of the particles appears to be determined by local variations in carbon concentrations, determined by distance to nearest neighbours and growth of austenite in adjacent regions $[15,16]$. Graphite particles forming early in solidification are not impinged by their neighbouring particles, and even though they are encapsulated in austenite they grow relatively fast. Particles forming later have to compete with neighbouring graphite for carbon and their growth is confined to relatively small volumes of liquid in late stages of solidification, which affects their growth rate as described by [17]. It can be shown that, at a critical solid fraction, graphite growth changes from free to impinged growth at which point growth rates are reduced significantly[18].

Figure 2a shows a 3D rendering of graphite particles, numbered P1 to P5, in a sub-volume different from that shown in Figure1. Figure $2 \mathrm{~b}$ shows a room temperature SEM image of the same particles revealing the internal graphite grains and metallic inclusions. In order to establish relationship between the particles' shape, volume and growth rate, the graphite particles can be characterised by their sphericity, $\Psi=\frac{\pi^{1 / 3}(6 V)^{1 / 3}}{A}$, where $\mathrm{V}$ is the object volume and A its surface area. $\Psi=1$ means that the object is perfectly spherical and less spherical objects have $\Psi<1$. Figure $2 \mathrm{c}$ and d shows sphericity as function of time and growth rate, respectively for the graphite particles shown in Figure $2 a$ and $b$. The dotted line in Figure $2 c$ indicates the end of solidification at approximately 480s.

Most particles are near spherical when they form, but the figure shows examples of how their shape can develop as they grow. Particles 1, 2 and 3 largely maintain sphericity; the variation in sphericity is a result of uncertainties in filtering, segmentation and rendering of volumes based on the acquired $\mathrm{X}$-Ray recordings.

Their final size varies so that P1 and P3 grow to become relatively large while P4, which forms later, remains small (Figure 2d). Particles 2 and 5 grow to the largest size while their sphericity is 
gradually reduced as they become more elongated. Figure 2 describes only few particles, but an analysis of a larger population of graphite particles in this sample shows that it is a general trend that the sphericity of individual particles decreases over time. However, because new near-spherical particles form continuously during solidification the average sphericity for the whole population remains nearly constant over time [15].

A particle that appears first time as a faint shadow in Figure $1 \mathrm{~b}$ (marked with a red circle) is seen in the subsequent frame as a spherical particle. Later, in Figures 1d-f, and $i$ it is seen to grow a protrusion. Figure 3 shows another example of such a type of particle that to begin with is spherical but develops a protrusion which subsequently accelerates the overall growth. Figure $3 \mathrm{a}$ is a LOM image of the serially sectioned sample that shows the initial spherical graphite particle (top right) in which conical sectors indicate graphite grains growing from the centre of the particle. The protrusion growing from the graphite sphere are graphite crystals that appear to grow approximately perpendicular to the length of the protrusion, and at the end it forms what appears to be a section of a graphite sphere.

As illustrated in Figure 4a, spherical graphite particles consist of graphite grains radiating from the centre. Growth of the particle occurs in the direction of the crystal's C-axis where a new layer nucleates and grows on top of the next [24-26]. Protrusions, as shown in Figure 4b. The orientation of the crystals is schematically drawn in Figure 4c. This type of graphite shape were described for the first time by Hamasumi [19] who found that the side branches to the trunk also grow by addition of graphene layers to the $\mathrm{C}$-direction of the graphite crystals.

Later Stefanescu et al. [20] describes similar structures and suggests that it is a transitional stage between spheroidal graphite and flake graphite. It is well established in the literature that contamination of elements like $\mathrm{O}, \mathrm{S}$ and others influence graphite growth and that also local segregation of said elements will lead to local variations in growth morphology. Normally the presence of these elements leads to a change in growth from the $\mathrm{C}$-direction to growth in the graphite crystals A-direction. However, in the protrusions shown here, growth continues to be in the $\mathrm{C}$-direction indicating the structure is not formed due to the presence of surface active trace elements. The above findings illustrate how non-spherical structures can form even in melts with low content of impurity elements. It has been discussed that such a change in growth behaviour occurs when a graphite sphere is in partial contact with the melt. [21-23] This can happen when graphite is trapped between branches of a dendrite or through liquidation cracking due to dynamic conditions during solidification [liquation cracking ref].

Based on the discussion above, we can consider some conditions under which certain factors can influence graphite growth in solidification of hypoeutectic cast iron with low $\mathrm{O}$ and $\mathrm{S}$ content:

\section{Growth in contact with the melt}

The first nodules form when the amount of primary austenite is small. They nucleate and grow in direct contact with the melt for a relatively short period of time. [27,28] In the present experiments it is difficult to see the very first part of nodule growth from nucleation to a size of 10-20 $\mu \mathrm{m}$ and it 
is expected that by the time graphite particles appear in the tomograms they are already encapsulated in austenite. However, graphite that grows freely in the melt appears to grow at a high rate as they have easy access to carbon from the melt. Diffusion of carbon in liquid cast iron is rapid, and in contact with the melt the flux of carbon to the nodule is high [1]. If the melt is "well treated" meaning that $\mathrm{Mg}, \mathrm{Ce}$ or other potent oxide and sulphide forming elements has been added to it, graphite will grow in the form of spheres as shown in Figure 4a[29]. The mechanism behind spheroidal growth has been discussed in the literature repeatedly, but recent investigations are able to show in detail how $\mathrm{Mg}, \mathrm{S}$ and $\mathrm{O}$ affect the growth conditions of the graphite crystals to promote spherical growth. [9] As the fraction solid increases, new graphite particles nucleate continuously in the remaining melt. It has been described how elements like $\mathrm{O}, \mathrm{S}$, Ti, etc. may segregate to the liquid pools to an extent where they are able to modify the growth mechanisms of graphite so that it no longer grows in spherical mode so that non-spherical particles may form directly in the melt. [29-31] However, the type of growth we see here is not of a type that should be expected under such conditions.

\section{Encapsulated growth}

Once encapsulated in austenite, the growth rate of graphite is controlled by diffusion of carbon through the austenite. The classical literature consider the case where the graphite sphere is encapsulated by a uniform shell of austenite, however, more recent research shows that primary dendrites significantly influence graphite growth so that the proximity of a dendrite to a nodule, whether it is encapsulated or un-encapsulated, will change the carbon concentration field so that it is no longer symmetrical.[20,27] In the present investigation it is found that graphite continues to grow while it is encapsulated and that the growth rate is restricted by the presence of neighbouring particles. Recent work [9] has shown that Mg can influence the growth mode of graphite when it grows in austenite to become less spherical. This may contribute to the formation of non-spherical shapes that are seen in the X-Ray recordings presented here. Protrusions formed in contact with austenite should grow at a moderate rate compared to graphite growing in direct contact with the liquid.

\section{Possible transition from encapsulated to growth in contact with the melt}

The 3D-tomography recordings show that non-spherical particles grow faster than regular spheres. Growth occurs primarily by extension of protrusions from a near-spherical particle. As described by Azeem el al. [14] variation in carbon and silicon concentration between dendrites in combination with stresses due to contraction and shrinkage during cooling, can break the austenite shell around a nodule so that it has direct contact with the liquid that has a high carbon content. During solidification, carbon is rejected to the liquid between dendrite arms so that the austenite solidus temperature is lowered. If, at the same time, local stresses occur it may be the cause of liquidation cracking as described in. [14] It means that austenite around a nodule can fracture so that the nodule gains access to the carbon enriched liquid. In contact with the liquid, the graphite can grow under conditions similar to a regular eutectic and at a higher rate than in the encapsulated state. In the 
protrusions shown in this investigation graphite continues to grow in the crystal's C-direction as it should be the case when the concentration of $\mathrm{O}$ and $\mathrm{S}$ in the liquid is low. It is therefore quite possible that the variation in sphericity that we see in quality ductile cast irons is inherent to the dynamics of solidification.

\section{Conclusion}

3D X-Ray tomography recordings of solidification of ductile cast iron can be a powerful tool to investigate precipitation and growth of graphite particles during solidification. When tomographic recordings are combined with serial sectioning and analysis in LOM and SEM detailed information about the particles' crystallography and growth can be obtained.

The transition of spherical graphite to non-spherical forms has been studied, and it is shown how graphite spheres can change shape due to local gradients in carbon concentration during solidification.

It is possible that the austenite encapsulating the graphite particles may break during solidification so that it gains access to liquid with high carbon content which allows a protrusion to form and grow at relatively high rate into the liquid.

\section{Acknowledgements}

MKB was supported financially by the Strategic Research Center 'REWIND0, Danish Research Council for Strategic Research, grant no. 10-093966. The authors would like to thank Diamond Light Source (DLS), UK, especially the remarkable support they received from the 112 beamline staff during the EE12204-1 beam time. This work would not have been possible without funding from Engineering and Physical Sciences Research Council (EPSRC, grant no. EP/I02249X/1) and Research Fund for Coal and Steel (RFCS, grant no. RFSR-PR-10005 DDT). MAA would like to thank Research Complex at Harwell for continuously supporting his research. MAA would also like to acknowledge funding from University Research Program of Ford Motor Company and NERC (NE/ M013561/1), a part of this paper was written while MAA was working on those projects.

Data statement: Due to its large size, the underlying raw data is not shared online, but representative sample data is included in the figures. The entire datasets are stored at DLS, and are available from the authors on reasonable request.

\section{References}

1. Cast Iron Science and Technology. (ed): Stefanescu, D.M. ASM International, 2017.

2. Roundtable discussion and closing section. . International Symposium on the Science and Processing of Cast Iron, SPCI-XI, Jönköping, Sweden (2017).

3. Stefanescu, D. M., Alonso, G., Larranaga, P, De la Fuente, E., and Suarez, R., Acta Materialia 139 (2017) p 109. 
4. de la Torre, Urko, Lacaze, Jacques, and Sertucha, Jon, International Journal of Materials Research 10711 (2016) p 1041.

5. Gerghu, Roxana, Magnusson Åberg, Lena, and Lacaze, Jacques, Materials Science Forum 3167 (2014) p 790.

6. Theuwissen, Koenraad, Lafont, Marie Christine, Laffont, Lydia, Viguier, Bernard, and Lacaze, Jacques, Transactions of the Indian Institute of Metals 656 (2012) p 627.

7. Muhmond, Haji Muhammad and Fredriksson, Hasse, Metallurgical Transactions A 4513 (2014) p 6187.

8. Muhmond, H. M. and Fredriksson, H., Metallurgical and Materials Transactions B 442 (2013) p 283.

9. Bourdie, Jacques. Sphéroïdisation du graphite - Cas de la fonte centrifugée. 1-133. 18-122017. PhD Thesis, Toulouse, France, Institut National Polytechnique de Toulouse (INP Toulouse).

10. Källbom, R., Hamberg, K., and Björkegren, Lars Erik, Institute of Cast Metals Engineers 67th World Foundry Congress, WfC06: Casting the Future 2 (2006) p 1071.

11. Mukherjee K., Fæster S.A, Hansen N., Dahl A.B., Gundlach Ca., Frandsen J.O., and Sturlason A., Materials Characterization 129 (2017) p 169.

12. Azeem, M. A., Lee, P. D., Phillion, A. B., Karagadde, S., Rockett, P., Atwood, R. C., Courtois, L., Rahman, K. M., and Dye, D., Acta Materialia 128 (2017) p 241.

13. Karagadde, S., Lee, P. D., Cai, B., Fife, J. L., Azeem, M. A., Kareh, K. M., Puncreobutr, C., Tsivoulas, D., Connolley, T., and Atwood, R. C., Nature Communications 6 (2015) p 8300.

14. Azeem, M. A., Bjerre, M. K., Atwood, R. C., Tiedje, N.S., and Lee, P. D., Acta Materialia 155(2018) p 393.

15. Bjerre, Mathias Karsten. In situ observations of graphite formation during solidification of cast iron. PhD Thesis, Technical University of Denmark, DTU Mechanical Engineering, Technical University of Denmark, 2800 Kongens Lyngby, Denmark. (2017).

16. Bjerre, Mathias Karsten, Azeem, Mohammed, Lee, Peter D., Hattel, Jesper Henri, and Tiedje, Niels Skat, Materials Science Forum 925 (2018) p 118.

17. Zhu, Mingfang, Zhang, Lei, Zhao, Honglei, and Stefanescu, Doru M., Acta Materialia, 84 (2015) p 413.

18. Bjerre, M. K., Azeem, M. A., Tiedje, N. S., Thorborg, J., Lee, P. D., and Hattel, J. H., Modelling and Simulation in Materials Science and Engineering (2018), Submitted for publication.

19. Hamasumi, Matsujiro, Transactions of the Japan Institute of Metals 64 (1965) p 234.

20. Stefanescu D.M., Alonso G. Larranaga P., and Suarez R., Acta Materialia 103 (2016) p 103.

21. Kallbom R, Hamberg, K., Wessen, M., and Bjorkegren, L. E., Materials Science and Engineering - A - Structural Materials 413-414 (2005) p 346.

22. Azeem M. A., Bjerre M. K., Atwood R. C., Tiedje N.S,, and Lee, P. D., Acta Materialia 155 (2018) p 393. 
23. Sertucha J., Suarez R., Asenjo I., Larranaga P., Lacaze J., Ferrer I., and Armendariz S., ISIJ International 492 (2009) p 220.

24. Lacaze, Jacques, Bourdie, Jacques, and Jesus Castro-Roman, Manuel, Acta Materialia 134 (2017) p 230.

25. Theuwissen K., Lacaze J., and Vacon M., Materials Characterization 95 (2014) p 187.

26. Velichko A., Holzapfel C., and Müklich, F., Advanced Engineering Materials 9 (2009) , p 39.

27. Rivera, G., Calvillo, P. R., Boeri, R., Houbaert, Y., and Sikora, J., Materials Characterization 599 (2008), p 1342.

28. Yamane, K., Yasuda, Hideyuki, Sugiyama, A., Nagira, T., Yoshiya, M., Morishita, K., Uesugi, K., Takeuchi, A., and Suzuki, Y., Metallurgical and Materials Transactions A (2015), p 4937.

29. Loper, C. R. Jr., AFS Transactions 77 (1969), p 1.

30. Wallace, J. F., Proc of the Int Symp on the Metall of Cast Iron, 2nd (1975), p 583.

31. Muhmond, Haji Muhammad and Fredriksson, Hasse, Materials Science Forum 3167 (2014), p 790. 


\section{Figures}

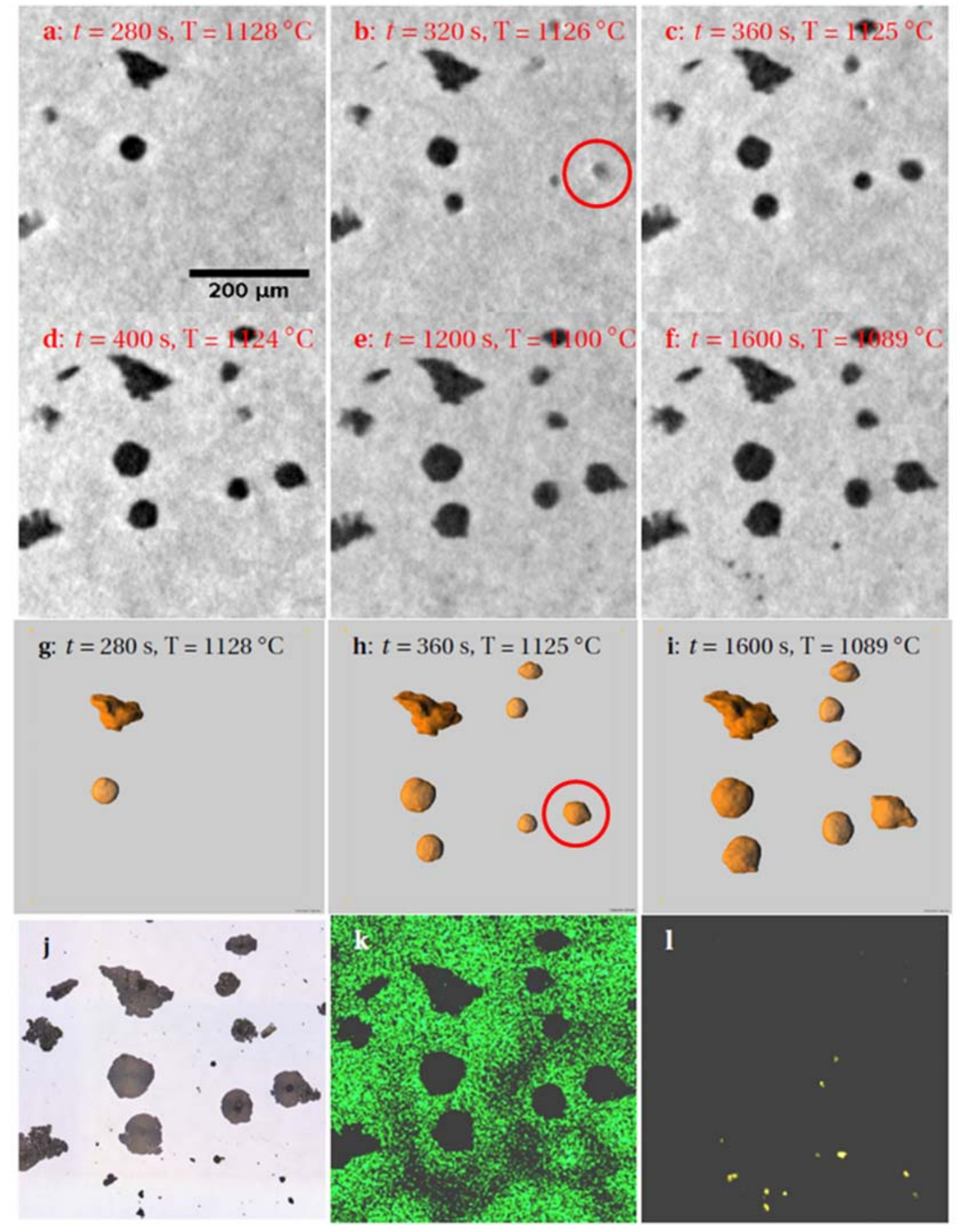

Figure 1: a-f: Time series showing 2D sections from tomograms at 6 time instances. Time and average temperature during recording are given in each frame. $\mathbf{g}$-I: $3 D$ renderings of selected graphite particles at three time instances corresponding to a-d. j: Room temperature microstructure obtained by LOM. $\boldsymbol{k} \& \boldsymbol{I}$ : EDS maps of silicon and magnesium respectively. 

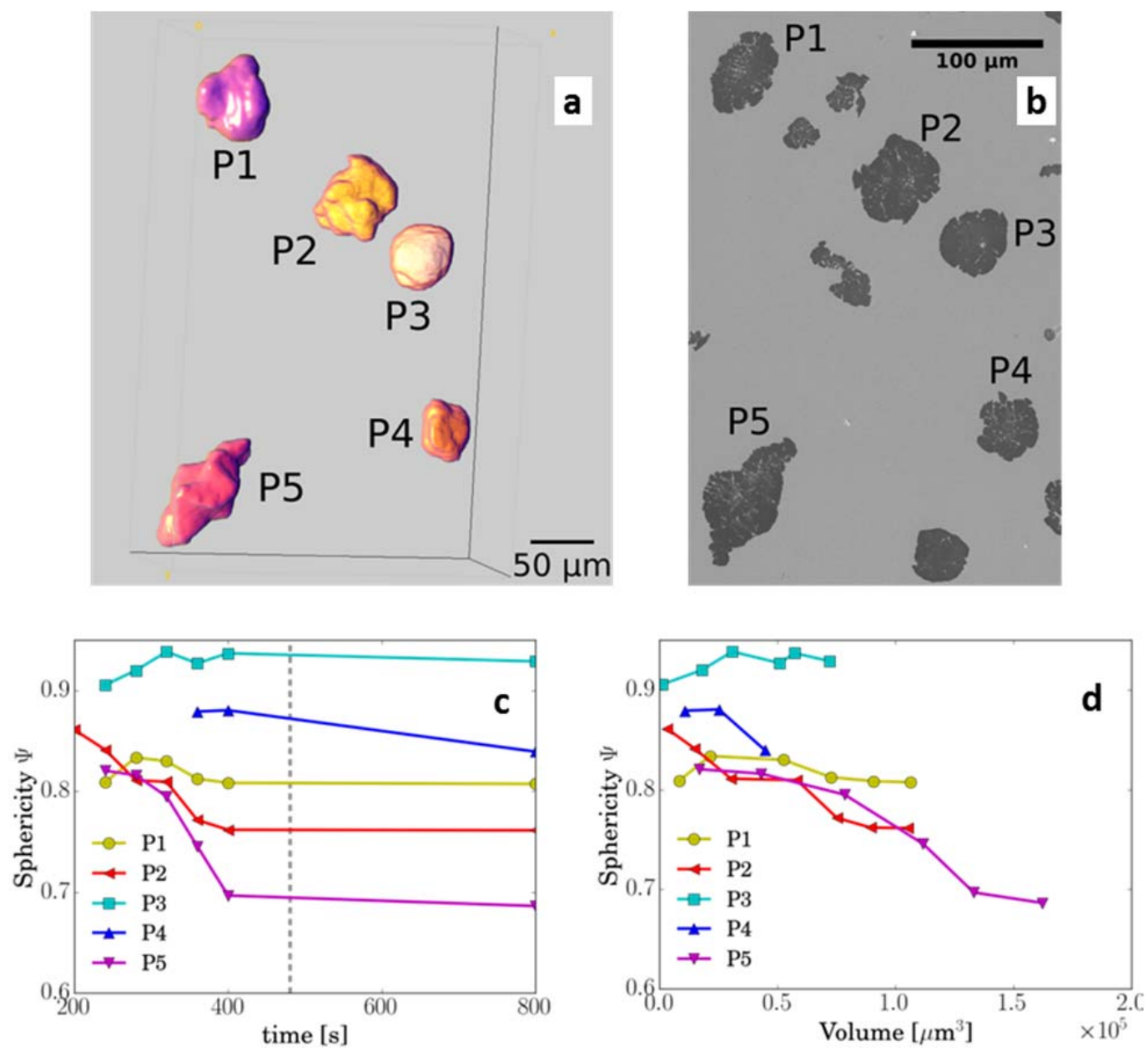

Figure 2: a: $3 D$ rendering of the graphite particles P1-P5 after solidification. $\boldsymbol{b}$ : Room temperature SEI where particles P1 to P5 are pointed out. $\boldsymbol{c} \& \boldsymbol{d}$ : Sphericity of P1-P5 as a function of time and particle volume. The approximate end of graphite precipitation is indicated by a vertical line in $a$. 


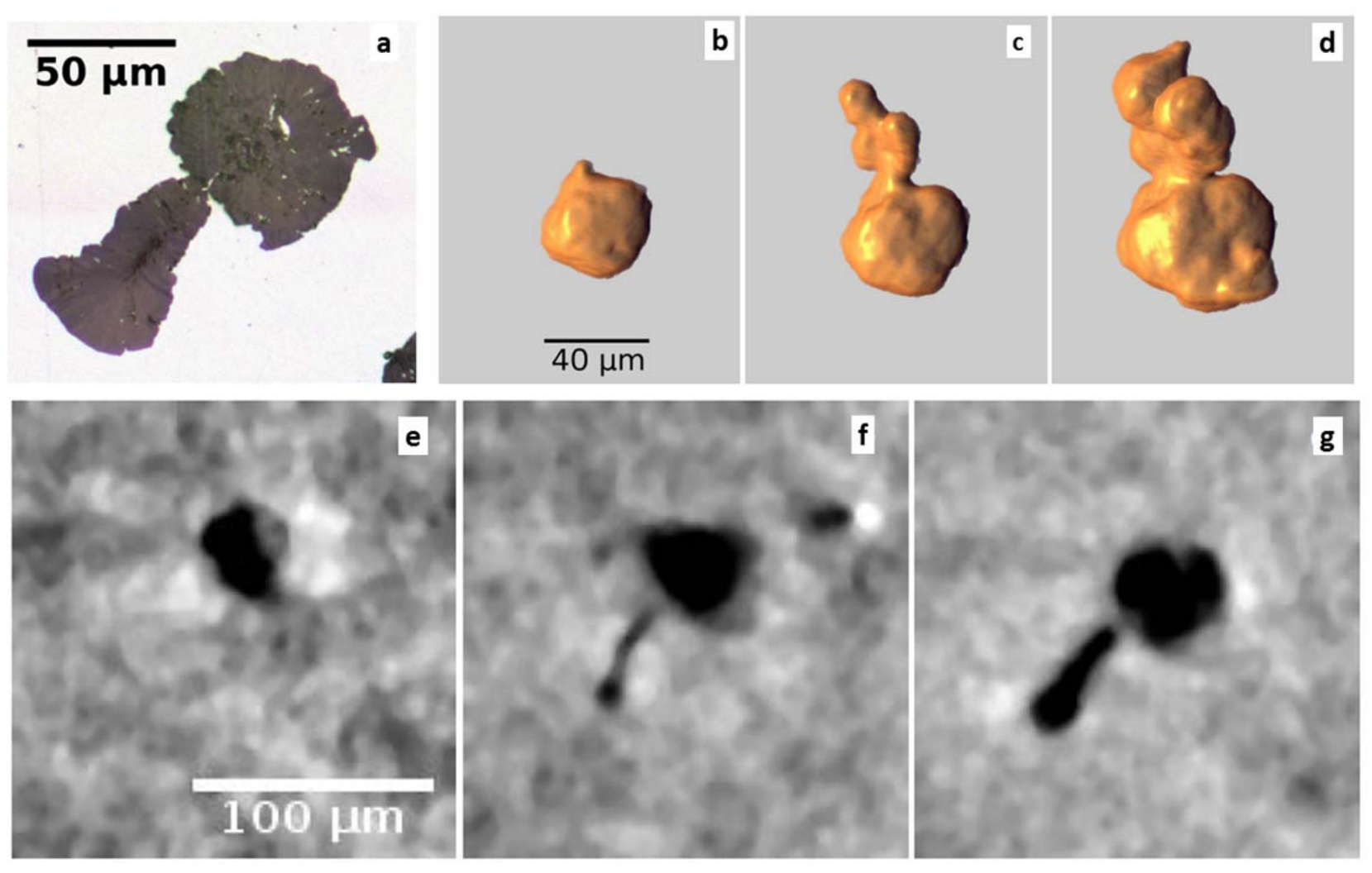

Figure 3: a: LOM image of graphite sphere with protrusion. $\boldsymbol{b}$-d: $3 D$ rendering of the particle in three stages of growth. $\mathbf{e - g}$ : $2 D$ sections from the recorded X-Ray tomograms taken equivalent to the image in Figure $3 a$. 

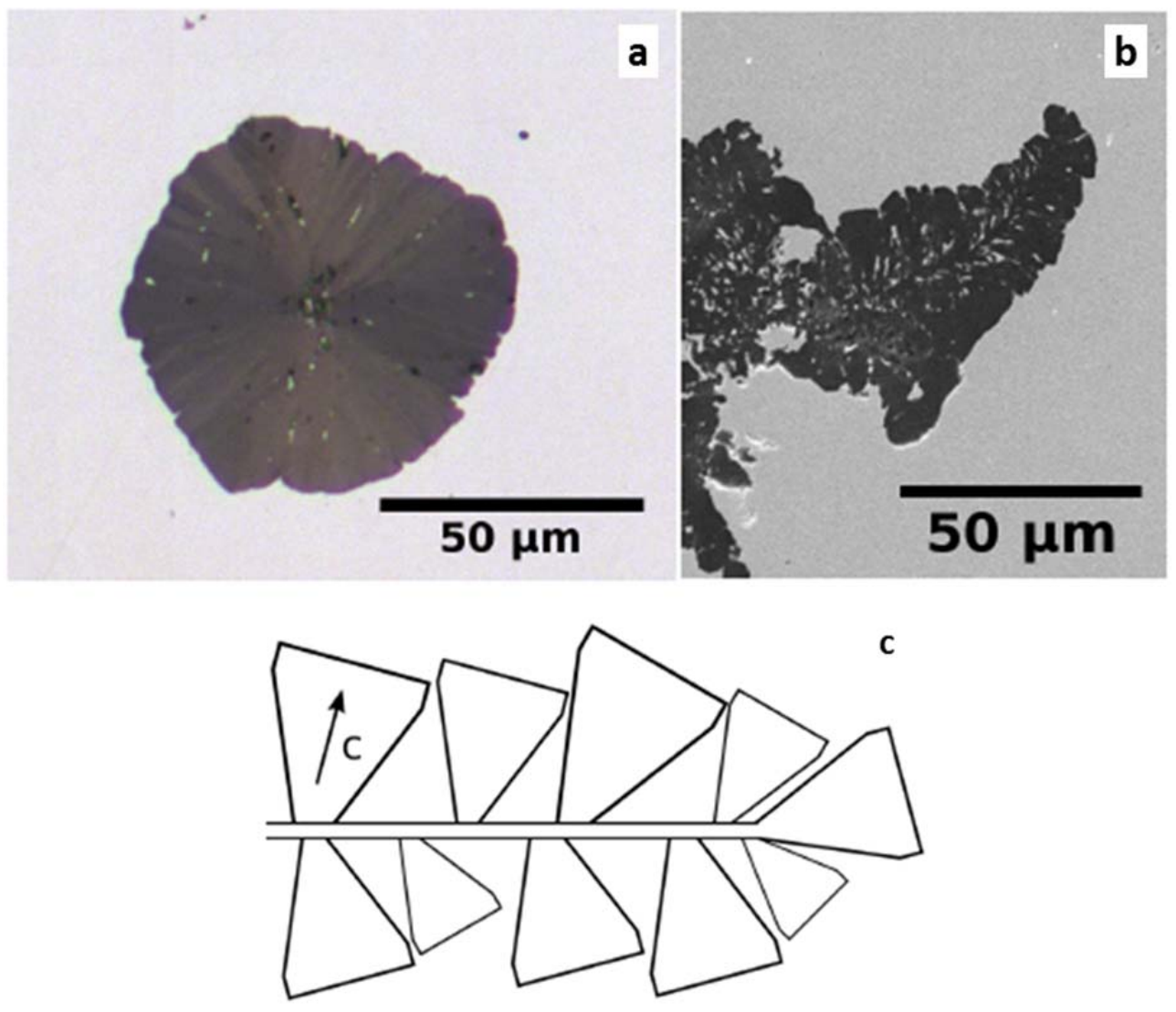

Figure 4: a: LOM image of spherical graphite particle with grains radiating from the centre and metallic inclusions between them. $\boldsymbol{b}$ : LOM image of protrusion from a graphite particle showing a dendrite-like structure. $c$ : Schematic of a graphite dendrite with a stem from which grains grow along the " $C$ " direction. 